\title{
A Technique to Suppress Mutual Coupling in Densely Packed Antenna Arrays Using Metamaterial Supersubstrate
}

\author{
Mohammad Alibakhshikenari ${ }^{14^{* *}}$, Ernesto Limiti ${ }^{1,4}$, and Bal Singh Virdee ${ }^{2}$ \\ ${ }^{1}$ Electronic Engineering Department, University of Rome "Tor Vergata”, Via del Politecnico 1, 00133 Rome - ITALY \\ ${ }^{2}$ London Metropolitan University, Center for Communications Technology \& Mathematics, School of Computing and \\ Digital Media, London N7 8DB, UK \\ ${ }^{3}$ Electrical and Computer Engineering Department, University of Manitoba, Winnipeg, Manitoba, CANADA \\ ${ }^{4}$ M.E.C.S.A., Microwave Engineering Center for Space Applications, Via del Politecnico 1, 00133 Rome - ITALY \\ *alibakhshikenari@ing.uniroma2.it
}

\begin{abstract}
A simple and practical technique for reducing the mutual coupling between neighbouring antennas is presented for application in densely packed antenna arrays. This is achieved by locating between the radiation elements a smaller patch with metamaterial decoupling structure (MTM-DS). In this case the radiating elements are circular patches and the MTM-DS is constructed from a hexagonal slit resonator. The consequence of implementing the MTM-DS patch is significant reduction in mutual coupling between adjacent radiating patches by $60 \%$, improvement in impedance match by $200 \%$ and substantial increase in the antenna's fractional bandwidth by $369 \%$. Since the ground plane is unaltered the frontto-back ratio is unaffected too. The proposed technique is easily realizable and can be used effectively in beam scanning applications.
\end{abstract}

Keywords- Mutual coupling, microstrip antennas, phased antenna arrays, metamaterial, beam scanning.

\section{INTRODUCTION}

Phased array antennas are becoming increasingly popular in communication networks particularly in radars and satellite-focused applications because they offer desirable characteristics of high gain, beam forming, and electronic beam scanning. To complement the high miniaturization standards of RF systems; microstrip phased arrays (MPAs) have been investigated extensively. MPA offers easy integration with other components making it suitable for compact RF system-in-package applications. MPA has been adopted widely for a range of wireless applications; however, it suffers from a trade-off between array performance and array size, as a result the mutual coupling in densely packed MPAs has been a real challenge as it degrades the arrays performance. This is because energy that should be radiated away is absorbed by the adjacent antenna. Similarly, energy that could have been captured by one antenna is instead absorbed by a nearby antenna. Hence, mutual coupling reduces the antenna efficiency and performance of antennas in both the transmit and receive mode.

Mutual coupling in antenna arrays, where the radiating elements are separated by half-wavelength or more, is dominated by surface wave effects. In densely packed arrays with element separation of less than halfwavelength suffer from both surface wave and spacewave coupling effects [1]. In multi-feed antennas, undesirable issue of mutual coupling among the radiating elements is usually overcome by using proper filtering functions [2], [3]. Various other techniques have also been proposed to suppress the effects of mutual coupling [4]-[14].

In this paper the undesirable effect of mutual coupling between neighbouring circular patch antennas is compensated with the inclusion of a metamaterial decoupling structure (MTM-DS) composed of a hexagonal slit resonator to create a metamaterial superstrate. It is shown that inclusion of the proposed MTM-DS the mutual radiation coupling between the antennas is significantly reduced. In addition, the impedance match and operational bandwidth improve with MTM-DS.

\section{RADIATION DECOUPLING STRUCTURE}

A unit element of metamaterial decoupling slit is shown in Fig.1. The optimized dimensions are given in Table I for X-band antenna which has been realized on Rogers RT6010 substrate with thickness of 2.54 $\mathrm{mm}$, dielectric constant $\left(\varepsilon_{r}\right)$ of 10.2 and $\tan \delta$ of 0.0023 . The hexagonal slits in the patch exhibit electric resonance for vertically polarized (polarized along zaxis) electric fields. Four hexagonal slits are combined to create a unit cell of MTM-DS. The effective permittivity and permeability of the MTM-DS can be calculated from scattering parameters of the structure as described in [15]. 


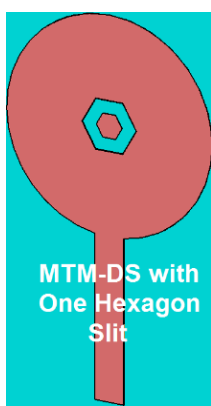

(a)

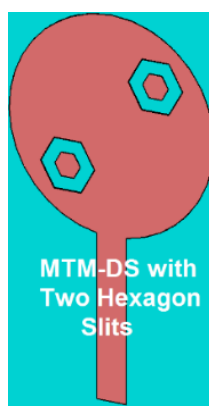

(b)

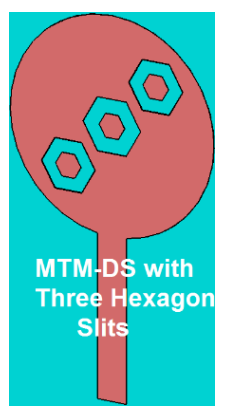

(c)

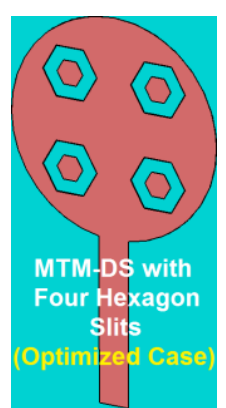

(d)

Fig.1. Metamaterial decoupling slit (MTM-DS) with hexagonal slits: (a) with one slit, (b) with two slits, (c) with three slits, and (d) with four slits (optimized case).

TABLE I. Antenna Dimensions (in millimeters).

\begin{tabular}{|c|c|c|c|c|c|c|c|c|}
\hline $\begin{array}{c}\text { Radiating } \\
\text { patch } \\
\text { radius }\end{array}$ & $\begin{array}{c}\text { MTM-DS } \\
\text { patch } \\
\text { radius }\end{array}$ & $\begin{array}{c}\text { Length of } \\
\text { antenna } \\
\text { feed-line }\end{array}$ & $\begin{array}{l}\text { Width of } \\
\text { antenna } \\
\text { feed-line }\end{array}$ & $\begin{array}{l}\text { Length of } \\
\text { substrate }\end{array}$ & $\begin{array}{l}\text { Width of } \\
\text { substrate }\end{array}$ & $\begin{array}{l}\text { Thickness } \\
\text { of substrate }\end{array}$ & $\begin{array}{c}\text { Radius of } \\
\text { MTM-DS } \\
\text { hexagon }\end{array}$ & $\begin{array}{c}\text { Width of } \\
\text { MTM-DS } \\
\text { slit }\end{array}$ \\
\hline 25 & 14 & 10.3 & 4 & 140 & 80 & 2.54 & 4 & 3 \\
\hline
\end{tabular}

\begin{tabular}{|c|c|c|c|c|}
\hline $\begin{array}{c}\text { Length of } \\
\text { ground } \\
\text { plane }\end{array}$ & $\begin{array}{c}\text { Width of } \\
\text { ground } \\
\text { plane }\end{array}$ & $\begin{array}{c}\text { Width of } \\
\text { structure } \\
\text { (antennas } \\
\# 1 \text { and \#2 } \\
\end{array}$ & $\begin{array}{c}\text { Length of } \\
\text { structure } \\
\text { (antennas } \\
\text { \#1 and \#2 } \\
\text { and MTM- } \\
\text { and MTM- }\end{array}$ & $\begin{array}{c}\text { Gap } \\
\text { between } \\
\text { MTM-DS } \\
\text { patch and } \\
\text { radiator }\end{array}$ \\
\hline 140 & & 35.3 & 66 & 1 \\
\hline
\end{tabular}

\section{IMPLEMENTATION OF MUtUAL RADiATION DECOUPLING IN MICROSTRIP PHASED ARRAYS}

The initial antenna array consists of two circular radiation patches, as shown in Fig. 2(a), which are excited through individual feed-lines. As described earlier the antenna array is constructed on Rogers RT6010 substrate. The antenna's reflection and transmission coefficient response (magnitude and phase) are shown in Fig. 3. Without the metamaterial decoupling structure the antenna operates over a frequency range from $9.55 \mathrm{GHz}$ to $10.0 \mathrm{GHz}$ for $\mathrm{S}_{11} \leq$ $10 \mathrm{~dB}$ with maximum impedance matching of $-13 \mathrm{~dB}$ at a resonance frequency of $10.73 \mathrm{GHz}$. In addition, the antenna's insertion loss over this frequency range varies from $-17 \mathrm{~dB}$ to $-19 \mathrm{~dB}$.

In order to minimise the degrading effects of mutual coupling between the two circular patches a metamaterial decoupling structure has been inserted between the two radiators, as shown in Fig. 2(b). The MTM-DS structure consists of four identical hexagonal slits embedded in a smaller patch. By doing this Fig. 2 confirms the antennas impedance bandwidth is increased, the insertion loss or attenuation between the two radiators increased and its operational bandwidth improved. Fig. 3 shows how the reflection and transmission coefficient responses are affected by increasing the number of hexagonal slits. Results of this analysis are given in Table II. It is evident that MTM-DS with one slit (i) substantially increases the fractional bandwidth by $369 \%$; (ii) attenuates the coupling between the two radiators over the bandwidth by $60 \%$ on average; and (iii) the significantly increases the impedance match by $200 \%$. By increasing the number of MTM-DS from one slit to four slits significantly erodes the fractional bandwidth, moderately reduces the attenuation of the radiation coupling and impedance match.

The antenna's radiation patterns are shown in Fig. 4 at its resonance frequencies of $9.86 \mathrm{GHz}$ and $10.16 \mathrm{GHz}$. The $3 \mathrm{~dB}$ beamwidth of the antenna is 34.5 degrees at $9.86 \mathrm{GHz}$, which increases to 51.8 degrees at $10.16 \mathrm{GHz}$.

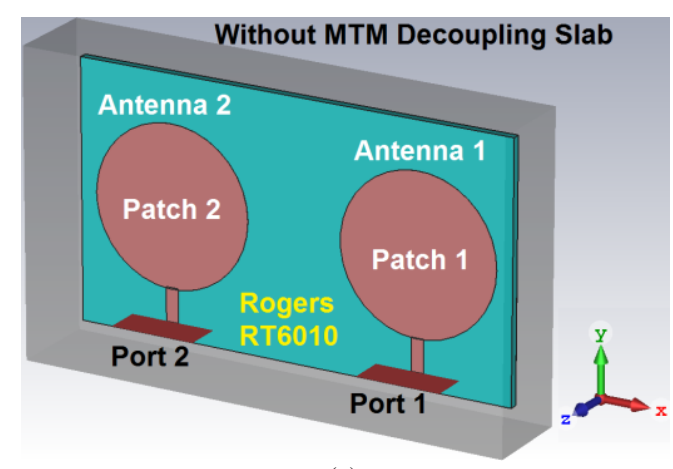

(a)

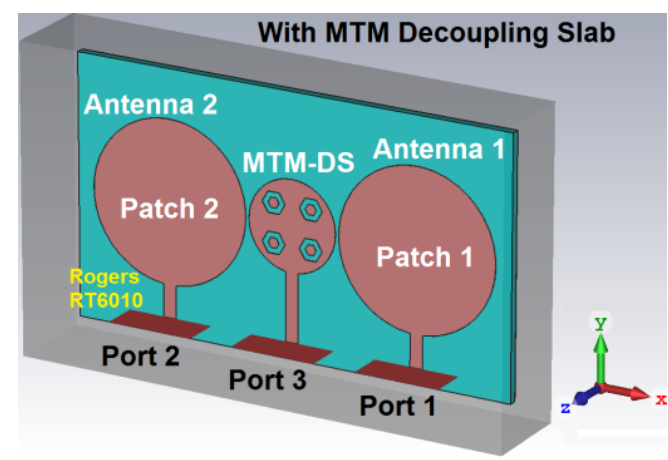

(b) 


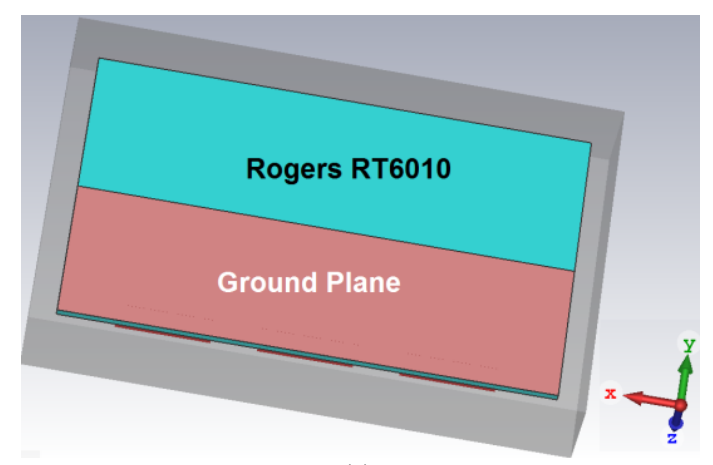

(c)

Fig.2. The proposed antenna structure: (a) without MTM-DS, (b) with multiple MTM-DS, and (c) ground plane of the antenna.
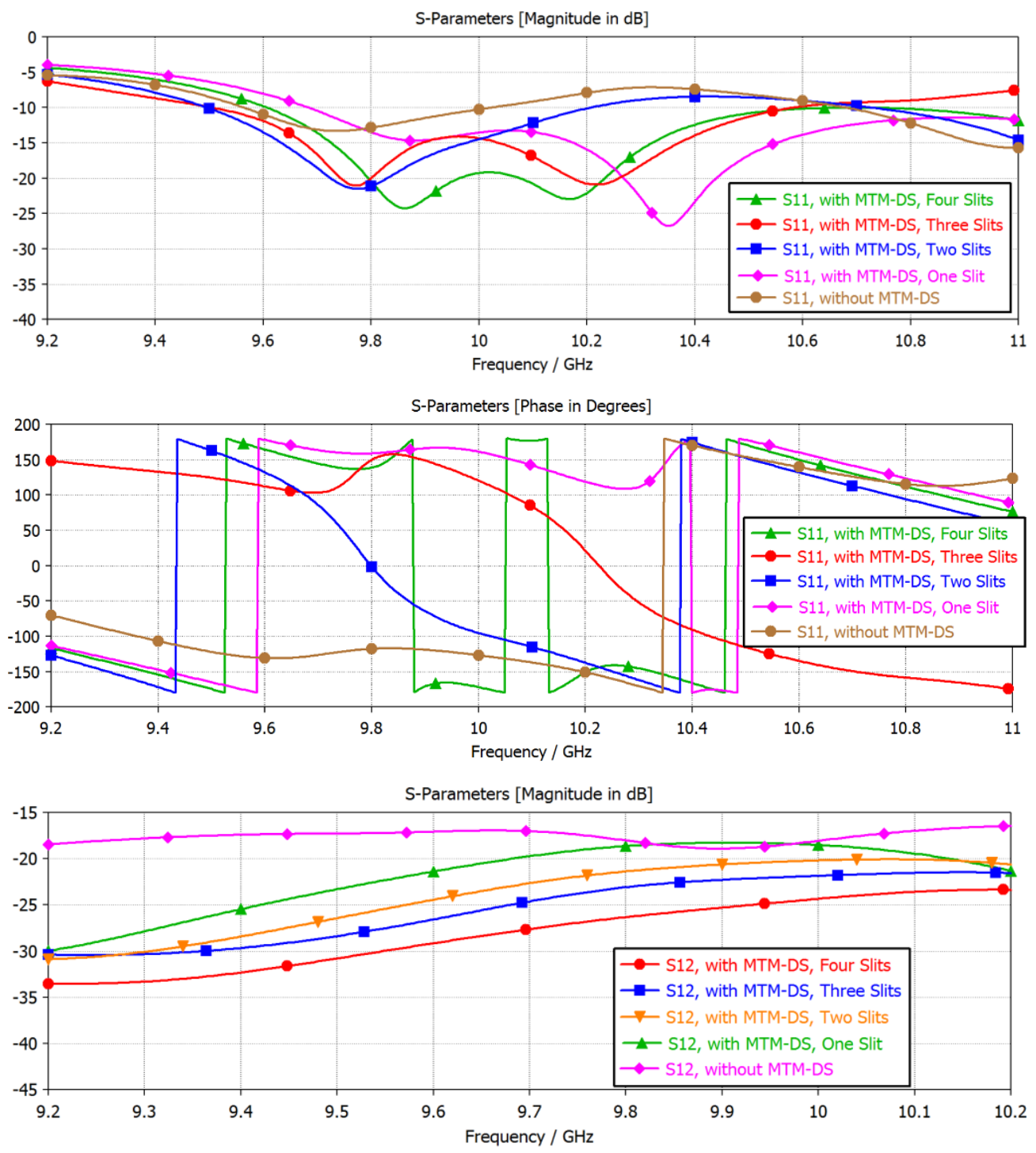


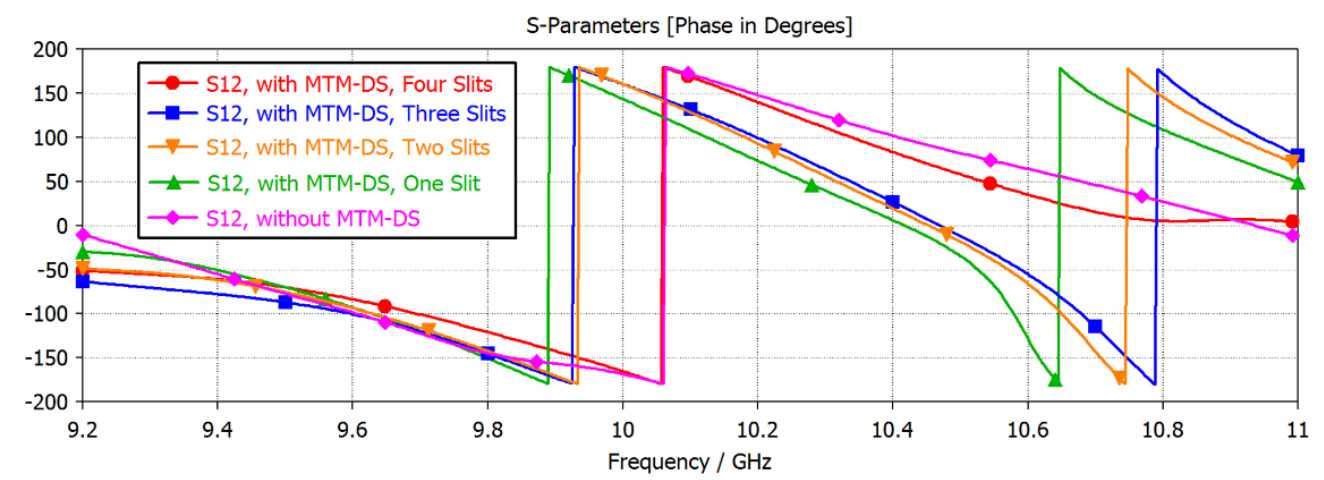

Fig.3. Reflection and transmission coefficient magnitude and phase response of the antenna array without and with MTM-DS mutual radiation decoupling structure. Response is also shown as a function of number of MTM-DS used.

TABLE II. PARAMETRIC STUDY ON S-PARAMETERS WITHOUT AND WITH MTM-DS

\begin{tabular}{|c|c|c|c|c|c|}
\cline { 2 - 5 } \multicolumn{1}{c|}{} & without MTM-DS & $\begin{array}{c}\text { MTM-DS with one } \\
\text { slit }\end{array}$ & $\begin{array}{c}\text { MTM-DS with two } \\
\text { slits }\end{array}$ & $\begin{array}{c}\text { MTM-DS with } \\
\text { three slits }\end{array}$ & $\begin{array}{c}\text { MTM-DS with four } \\
\text { slits }\end{array}$ \\
\hline $\mathbf{S}_{\mathbf{1 1}}$ (GHz) & 9.55 to 10.0 & 9.7 to 11.5 & 9.5 to 10.2 & 9.5 to 10.6 \\
\hline $\begin{array}{c}\text { Fractional } \\
\text { Bandwidth (\%) }\end{array}$ & 4.6 & 16.98 & 7.1 & 10.94 \\
\hline $\mathbf{S}_{\mathbf{1 2}}$ (dB) & -17 to -19 & -20 to -40 & -20 to -26 & -21 to -31 \\
\hline $\begin{array}{c}\text { Max. Impedance } \\
\text { Matching (dB) }\end{array}$ & -13 & -26 & -21 & -23 to -30 \\
\hline
\end{tabular}
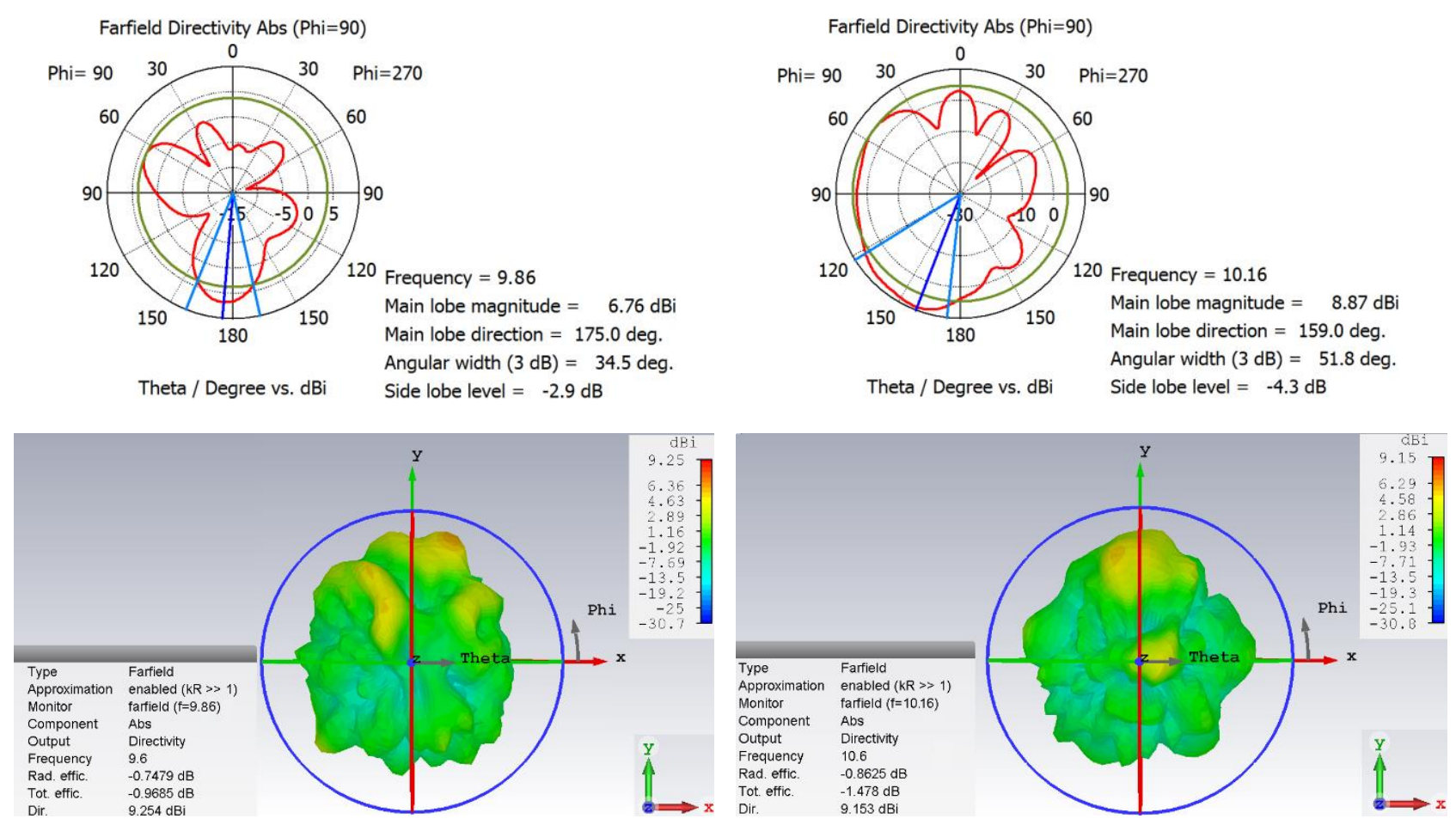

Fig.4. Two and three dimensional radiation patterns of the proposed antenna with MTM-DS with four hexagonal slits at the resonance frequencies of $9.86 \mathrm{GHz}$ and $10.16 \mathrm{GHz}$.

\section{CONCLUSION}

The feasibility of reducing the radiation coupling between adjacent antennas, which is encountered in densely packed antenna arrays, has been demonstrated using metamaterial decoupling structure. The proposed technique is simple to implement and incorporate in the antenna array. The metamaterial decoupling structure is a hexagonal slit etched in a smaller patch which is inserted between radiating patches. Reduction in undesirable coupling between two radiator is $60 \%$ on average over the operational bandwidth of the antenna. The benefit of this technique is substantial increase in the fractional bandwidth by $369 \%$.

\section{REFERENCES}

[1] M. Nikolic, A. Djordjevic, and A. Nehorai, "Microstrip antennas with suppressed radiation in horizontal directions and reduced 
coupling," IEEE Trans. Antennas Propag., vol. 53, no. 11, pp. 34693476, Nov. 2005.

[2] H. Chreim et al., "An enhanced Ka -band reflector focal-plane array using a multifeed EBG structure," IEEE Antennas Wireless Propag. Lett., vol. 9, pp. 1152-1156, Dec. 2010.

[3] H. Chreim et al., "Analysis of capabilities to achieve overlapped radiating apertures by using a multi-feed EBG structure loaded by passive filtering functions," in Proc. Conf. Antennas Propag., 2010, pp. 1-5.

[4] H. Asieh, J. Nourinia, and C. Ghobadi, "Mutual coupling reduction between very closely spaced patch antennas using lowprofile folded split-ring resonators (FSRRs)," IEEE Antennas Wireless Propag. Lett., vol. 10, pp. 862-865, Sep. 2011.

[5] F. Yang and Y. Rahmat-Samii, "Microstrip antennas integrated with electromagnetic band-gap (EBG) structures: A low mutual coupling design for array applications," IEEE Trans. Antennas Propag., vol. 51, no. 10, pp. 2936-2946, Oct. 2003.

[6] H. S. Farahani, M. Veysi, M. Kamyab, and A. Tadjall, "Mutual coupling reduction in patch antenna arrays using a UC-EBG superstrate," IEEE Antennas Wireless Propag. Lett., vol. 9, pp. 5759, Mar. 2010.

[7] K. Buell, H. Mosallaei, and K. Sarabandi, "Metamaterial insulator enabled superdirective array," IEEE Trans. Antennas Propag., vol. 55. no. 4, pp. 1074-1085, Apr. 2007.

[8] M. F. Shafique, Z. Qamar, L. Riaz, R. Saleem, and S. A. Khan, "Coupling suppression in densely packed microstrip array using metamaterial structure," Microw. Opt. Technol. Lett., vol. 57, no. 3, pp. 759-763, 2015.

[9] G. Shaker, G. Rafi, S. Safavi-Naeini, and N. Sangary "A synthesis technique for reducing mutual coupling between closely separated patch antennas," in Proc. Int. Symp. Antennas Propag. Soc., 2008, pp. 1-4.

[10] A. Diallo, C. Luxey, P. L. Thuc, R. Staraj, and G. Kossiavas Aliou, "Study and reduction of the mutual coupling between two mobile phone PIFAs operating in the DCS1800 and UMTS bands," IEEE Trans. Antennas Propag., vol. 54. no. 11, pp. 3063-3074, Nov. 2006.

[11] A.Wahid, M. Sreenivasan, and P. H. Rao, "CSRR loaded microstrip array antenna with low side lobe level," IEEE Antennas Wireless Propag. Lett., vol. 14, pp. 1169-1171, May 2015.

[12] R. Hafezifard, M. N. Moghadasi, J. R.Mohassel, and R. A. Sadeghzadeh, "Mutual coupling reduction for two closely spaced meander line antennas using metamaterial substrate," IEEE Antennas Wireless Propag. Lett., vol. 15, pp. 40-43, Feb. 2015, doi: 10.1109/LAWP.2015.2427235.

[13] M. M. Bait-Suwailam, O. F. Siddiqui, and O. M. Ramahi, "Mutual coupling reduction between microstrip patch antennas using slittedcomplementary split-ring resonators," IEEE Antennas Wireless Propag. Lett., vol. 9, pp. 876-878, Sep. 2010.

[14] Z. Qamar, U. Naeem, S. A. Khan, M. Chongcheawchamnan, and M. F. Shafique, "Mutual coupling reduction for highperformance densely packed patch antenna arrays on finite substrate," IEEE Trans. Antennas Propag., vol. 64, no.5, pp. 16531660, May. 2016.

[15] D. R. Smith, S. Schultz, P. Markos, and C. M. Soukoulis "Determination of effective permittivity and permeability of metamaterials from reflection and transmission coefficients," Phys. Rev. B, vol. 65, no. 195104, pp. 1-5, 2002. 